\title{
Analysis of Isoforms of Protein Disulfide Isomerase in Plants by Immunomicroscopy
}

\author{
Dong-Ping Lu* and David A. Christopher*
}

*Department of Molecular Biosciences \& Bioengineering, University of Hawaii, 1955 East-West Rd. Honolulu, HI 96822

Protein disulfide isomerases (PDIs) are oxidoreductases that catalyze the formation, reduction, and isomerization of disulfide bonds in newly synthesized secretory proteins in the lumen of the endoplasmic reticulum, ER [1]. PDI-mediated disulfide bond formation in the target proteins is necessary for their proper folding, stability, catalytic activity and interaction with other proteins [2]. PDIs alter disulfide bonds via their integral redox-active thioredoxin-domain, which classifies them in the superfamily of thioredoxin-like proteins $[3,4,5]$.

In animals and yeast, PDIs have diverse cellular functions that surpass the traditional folding of proteins in the ER. PDIs are required for cell viability, ion uptake, activating gene transcription and cell differentiation $[4,7,8]$ and are found in the nucleus, cytoplasm, ER, mitochondria and extracellular environment $[9,10]$. They resemble chaperones by preventing proteins from aggregating and are indispensable subunits in numerous enzyme complexes [11,12].

In plants, PDIs have been shown to assist with the folding of storage proteins during the biogenesis of protein bodies in the seed endosperm [13]. In maize, a PDI functions in concert with $\mathrm{BiP}$ at different stages of zein processing and assembly into protein bodies, serving as a chaperone [13]. In rice seeds, a PDI prevents the aggregation of proglutelin and prolamin by assisting with their segregation in the ER lumen [14]. In Arabidopsis, the expression of some PDI genes is upregulated by the unfolded protein response [15].

Evidence for a PDI in chloroplasts has come from the unicellular green alga, Chlamydomonas reinhardtii [16]. This chloroplast PDI, which is designated as RB60, forms a complex with at least three other proteins [17]. Light stimulates binding of the PDI-RB60 complex to the 5' untranslated region of the $p s b A$ mRNA (5' UTR), which activates translation and synthesis of the $p s b A$ gene product, the D1 membrane protein of photosystem II [17]. Because translation of the $p s b A$ mRNA in vascular plants is light activated [18] and the Arabidopsis $p s b A$ mRNA 5' UTR interacts with redox-regulated RNA-binding proteins [19], it is hypothesized that an analogous redox-regulatory system exists in higher plant chloroplasts and mitochondria [20]. However, no studies on PDI-orthologs in these plant organelles have been reported.

We used antisera generated against the chloroplast protein disulfide isomerase (PDI) RB60 from the unicellular alga, Chlamydomonas reinhardtii, in the immunoblot analysis of Arabidopsis (Arabidopsis thaliana) chloroplast subfractions, and via immuno-fluorescence microscopy and transmission electron microscopy of Arabidopsis leaves. Two abundant immunorelated PDI isoforms of 52 and $68 \mathrm{kDa}$ were detected in Arabidopsis chloroplasts. They were mainly associated with different regions of the starch grain, while a secondary protein was also detected in the cell wall or plasma membrane at a relatively low level. The $68 \mathrm{kDa}$ PDI-like protein was associated with the stroma-starch interface at one end of the developing starch grain, while the $52 \mathrm{kDa}$ PDI-like protein 
was distributed randomly in the mature regions of the grain. The significance of these associations are discussed.

[1] Frand AR, Kaiser CA (1998) Mol Cell 1:161-170

[2] Aslund F, Beckwith J (1999) Cell 96: 751-753

[3] Kanai S, et al. (1998) J Mol Evol 47: 200-210

[4] Ferrari DM, Soling HD (1999) Biochem J 339:1-10

[5] Meiri E, et al. (2002) Mol Genet Genomics 267: 231-240

[6] Markus M, Benezra R (1999) J Biol Chem 274:1040-1049

[7] Ohtani H, et al. (1993) Histochemistry 100: 423-429

[8] Fornes MW, Bustos-Obregon E (1994) Andrologia 26: 87-92

[9] Rigobello MP, Donella-Deana A, Cesaro L, Bindoli A (2001) Biochem J 356: 567-570

[10] Turano C et al. (2002) J Cell Physiol 193: 154-163

[11] Lumb RA, Bulleid NJ (2002) EMBO J 21: 6763-6770

[12] Lamberg A, et al. (1996) Biochem J 315: 533-536.

[13] Li CP, Larkins BA (1996) Plant Mol Biol 30: 873-882

[14] Takemoto Y, et al. (2002) Plant Physiol 128:1212-1222

[15] Martinez IM, Chrispeels MJ (2003) Plant Cell 15: 561-576

[16] Trebitsh T, et al. (2001) J Biol Chem 276: 4564-4569

[17] Kim JM, Mayfield SP (1997). Science 278:1954-1957

[18] Mattoo AK, et al. (1989) Cell 56: 241-246.

[19] Shen Y, et al. (2001) Plant Cell Physiol 42:1071-1078

[20] Levings III CS, Siedow JN (1995) Science 268: 695-696

[21] This research is supported by NSF grant No. MCB03-48028 to DAC. We thank Tina M. Weatherby of the University of Hawaii Biological Electron Microscope Facility for expert technical assistance. 